\title{
Correction to: Zonally asymmetric mode of anomalous activity in summer Asian subtropical westerly jet and its possible sources
}

Di Li $^{1,2,3}$ (D) Haishan Chen ${ }^{4,5,6} \cdot$ Peng Liu ${ }^{4,5,6} \cdot$ Changyan Zhou ${ }^{1,2}$

Published online: 29 January 2020

(C) Springer-Verlag GmbH Austria, part of Springer Nature 2020

Correction to: Theoretical and Applied Climatology (2020) 139:17-32

https://doi.org/10.1007/s00704-019-02934-5
The original version of this article unfortunately contained a mistake. The presentation of Fig. 4 was incorrect. The corrected figure is given below. The publisher regrets this mistake.
Fig. 4 Correlation between PC2 and simultaneous summer upper layer soil moisture anomalies. Dots indicate significant at the 95\% confidence level

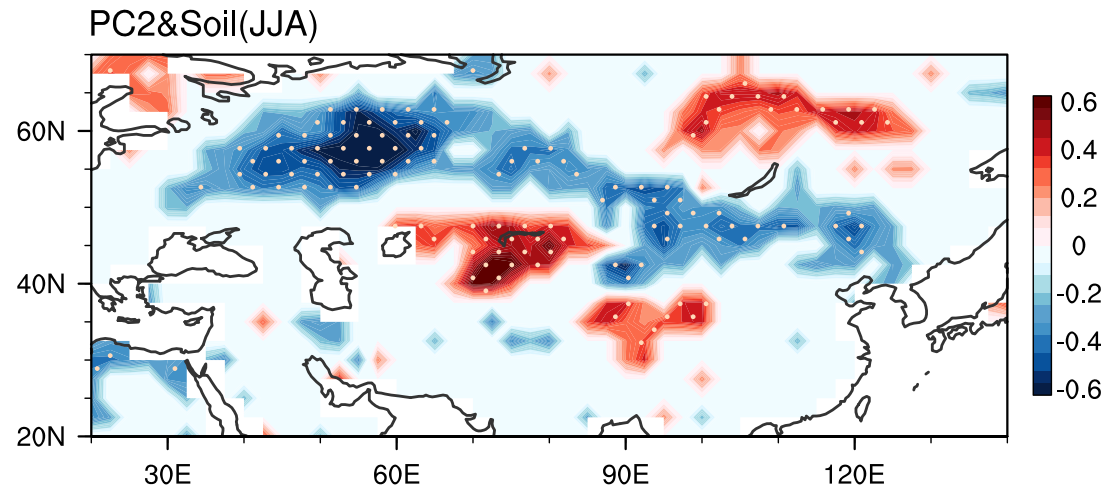

The online version of the original article can be found at https://doi.org/ 10.1007/s00704-019-02934-5

Di Li

lidi_ipm@163.com

1 Institute of Plateau Meteorology, China Meteorological Administration, Chengdu, China

2 Heavy Rain and Drought-Flood Disasters in Plateau and Basin, Key Laboratory of Sichuan Province, Chengdu, China

3 Plateau Atmosphere and Environment, Key Laboratory of Sichuan Province, Chengdu, China

4 Key Laboratory of Meteorological Disaster, Ministry of Education, Nanjing, China

5 International Joint Research Laboratory of Climate and Environment Change, Nanjing, China

6 Collaborative Innovation Center on Forecast and Evaluation of Meteorological Disasters, Nanjing University of Information Science \& Technology, Nanjing, China 